\title{
Spider web survey or whole plant visual sampling? Impact assessment of $B t$ corn on non-target predatory insects with two concurrent methods
}

\author{
Ferenc TÓTH ${ }^{1 *}$, Krisztina ÁRPÁS ${ }^{1}$, Dóra SZEKERES ${ }^{1}$, Ferenc KÁDÁR ${ }^{2}$, Ferenc SZENTKIRÁLYI' \\ Ágnes SZÉNÁSI ${ }^{1}$ and József KISS ${ }^{1}$ \\ ${ }^{1}$ Szent István University, Faculty of Agricultural and Environmental Sciences, Department of Plant Protection, H-2103 Gödöllö, \\ Páter K. u. 1, Hungary \\ ${ }^{2}$ Plant Protection Institute of Hungarian Academy of Sciences, Department of Zoology, H-1022 Budapest, Herman Ottó út 15, Hungary
}

\begin{abstract}
Impact assessment studies rely on relevant sampling methods. Correct evaluation of methods can be done by their concurrent use in the same sampling site and period. Collecting webs of Theridion impressum L. Koch (Araneae: Theridiidae) may serve as an arthropod sampling method: empty cuticles of prey items remain attached to the back side of the leaves with adhesive silk. Our study aimed to compare the applicability of the two methods concurrently (spider web survey and whole plant visual sampling) in a risk assessment study. The spider web survey recorded more predatory insect families than the whole plant visual sampling. Both methods were able to detect significant differences in the quantity of predatory insects in Bt vs. isogenic plots, but not in the same taxa (Nabidae: spider-web, 2001, Bt > Iso; Coccinellidae: plant sampling, 2001, Iso > Bt; Welsh-test, $P<0.05)$; thus, they could not confirm each other. The lack of confirmation can be explained by differences in the sensitivity and selectivity of the two methods. A web survey of $T$. impressum has the practical advantage that although we concentrate only on the one species during field sampling, we gain additional information on a wide range of foliage-dwelling arthropods. Due to several biological uncertainties, interpretation and explanation of the results remain problematic. Thus, additional research - based on in-situ observation and recording of $T$. impressum-prey interactions - is necessary before we could propose web survey method as a complementary tool in ecological impact assessment.
\end{abstract}

Keywords: Bt transgenic corn / Cry1Ab / Theridion impressum / Theridiidae / spider-web / plant sampling / impact assessment / non-target

\section{INTRODUCTION}

In 2003, GM crops covered 67.7 million hectares globally, of which 12.2 million hectares were planted with $B t$ crops. The dominant $B t$ crop was $B t$ corn, planted on 9.1 million hectares (James, 2003). Non-target effects of transgenic plants were studied mostly on Bt corn resistant to Ostrinia nubilalis (Dutton et al., 2003). A relatively large number of open field plot studies surveyed predator groups in Bt corn (Bourguet et al., 2002; Lozzia, 1999; Lozzia et al., 1998; Manachini, 2000; Wold et al., 2001), including spiders (Candolfi et al., 2004; Dively and Rose, 2002; Lozzia and Rigamonti, 1998; Pilcher et al., 1997; Volkmar et al.,
2004). Although the importance of spiders in agroecosystems was indicated by a series of arachnological reviews (Bogya and Mols, 1996 - 457 refs.; Greenstone, 1999 - 107 refs.; Hodge, 1999 - 111 refs.; Nyffeler, 1999 - 62 refs.; Nyffeler and Sunderland, 2003 - 360 refs.), none of the recent GMO impact assessment studies dealt with a detailed analysis of any one particular spider species.

Within the framework of a 3-year project, we assessed the impact of $B t$ corn on the phytophagous and predatory arthropod assemblages as compared to isogenic corn (Kiss et al., 2003). In order to assess the

\footnotetext{
* Corresponding author: toth.ferenc@mkk.szie.hu
} 
cumulative indirect effects of $B t$ corn on non-target arthropod assemblages through trophic interactions, we have established a tetratrophic field study model. The potential test spider species must meet several requirements: frequently occurs on the area, actively occupies it throughout the vegetation period, has a relatively large prey range (captures target and non-target organisms, phytophagous, parasitoid and predator species), has an easy to follow reproduction cycle, and is little disturbed by our investigation. According to our field studies since 1998 and similar to our study plots, the most abundant foliage-dwelling cursorial (hunter) spider families in Hungarian cornfields are Thomisidae and Philodromidae, while the most abundant web-builder families are Linyphiidae, Theridiidae, Araneidae and Tetragnathidae (Tóth unpublished; Tóth et al., 2002). The same web-builder spider families were found to be dominant in cornfields in Germany (Ludy and Lang, 2004). Since cursorial spiders capture a maximum of only 1-2 prey a day (Greenstone, 1999; Nyffeler and Benz, 1988), their predation is difficult to monitor. Linyphiid, araneid and tetragnathid spiders all build webs, but their prey is crushed during consumption and all residues are thrown out of the web. Due to this special feeding habit, their prey range is difficult to assess. In contrast, theridiid spiders allow us to monitor the prey species because they leave the cuticles of their prey intact and finely incorporate every captured arthropod into the web. Theridiid space webs usually last longer (typically several weeks) than orb-webs, which last only a few days at most (Zschokke, 2000). Therefore, examination of web content provides information not only about the immediate prey-capture activity of the spider, but that of the past few weeks as well.

The most abundant theridiid spider in our plots was Theridion impressum, a species used earlier as a test organism in both laboratory and field studies (Pekár, 1998, 1999, 2002; Schröder et al., 1999; Tóth et al., 1998, 2000, 2001, 2002). T. impressum is widely distributed in Europe, Asia and North America up to $2000 \mathrm{~m}$ above sea level (Heimer and Nentwig, 1991). This species was recorded in 30 different habitat types including sandy beaches, coastal dunes, moist littoral areas, raised bogs, hummock areas, areas with mire pines, dwarf shrub heaths, orchards, arable fields, dry and wet grasslands, etc. (Hanggi et al., 1995; Samu and Szinetár, 1999). It was also a dominant species in apple and pear orchard canopies (Bogya, 1999), and at the foliage level in cornfields (Tóth et al., 2002).

T. impressum has a broad prey spectrum, capturing practically every arthropod taxon that could be observed on corn plants (Árpás et al., 2004). Nyffeler et al. (1994) found that this spider species often captured aphids. According to Pekár (2000), T. impressum captured mostly aphids $(73 \%$ of the total number of captured individuals), Diptera (7.5\%), Coleoptera and Hymenoptera (both 5.4\%). Pests comprised $90 \%$ of the total web content; natural enemies, pollinators and other insects sampled in sunflower, phacelia and apple, accounted for the remaining $10 \%$.

T. impressum prefers to build dense, tangled, threedimensional webs (including a central retreat) on low vegetation (Roberts, 1995). As is typical of theridiids, bodies of captured arthropods or empty cuticles of consumed prey are attached to the web with adhesive silk. The web fills the space between two adjacent leaves in corn. Analysis of T. impressum web contents was found to be suitable to detect differences between arthropod assemblages of $B t$ vs. isogenic corn plots (Árpás et al, 2004).

It is known that every sampling method is selective overestimating the density of certain taxa while underestimating others (Sunderland et al., 1995). Therefore, it is strongly recommended to use at least two complementary sampling methods when not one species, but an entire community or assemblage is being monitored. Instantaneous, snapshot methods, like whole plant visual sampling, are presumably biased at least by the actual weather and the daily activity pattern of arthropods, so these should be complemented with at least one cumulative method, such as web content analysis of $T$. impressum. Our study aimed to compare the applicability of the two methods concurrently (spider web content and whole plant visual sampling) in a risk assessment study, and to test if one of the methods detected any difference between insect assemblages of $B t v s$. isogenic corn and if the other method would confirm it.

\section{RESULTS AND DISCUSSION}

According to the combined data of the two methods, a total of 20 predatory insect families were identified in the experimental plots; two of them (Ens.: Oecanthidae, Tettigoniidae) were recorded exclusively by whole plant visual sampling, and seven of them (Col.: Histeridae, Cantharidae, Cleridae, Anthicidae; Hym.: Formicoidea, Vespidae; Dipt.: Asilidae) were found only in the spider webs; while 11 families were recorded by both methods (Derm.: Forficulidae; Thys.: Aelothripidae; Het.: Nabidae, Anthocoridae, Miridae; Neur.: Chrysopidae, Hemerobiidae, Col.: Carabidae, Coccinellidae, Staphylinidae; Dipt.: Syrphidae). 
During both years, Coccinellidae were the dominant predators in whole plant visual samples. In contrast, compared to other predatory taxa, only a few individuals of Coccinellidae were found in the webs of $T$. impressum in both years, while Anthocoridae were dominant in 2001 and Chrysopidae in 2002. Significant differences (Bt vs. isogenic) were found in two cases: Nabidae (spider-web, 2001, $B t>$ Iso, $P<0.05$ ) and Coccinellidae (plant sampling, 2001, Iso $>B t, P<0.05$ ) (Fig. 1).

Hierarchical Cluster Analysis did not separate data of individual plots by treatment (Bt vs. isogenic), but instead separated them by sampling method (plant sampling $v s$. spider-web) (Fig. 2). This classification was checked and confirmed by NMDS, so results suggest that the impact of treatment ( $B t v s$. Iso) was quantitatively of minor importance compared to differences between methods. Consistency of the two methods seemed to be similar in 2001, but in the next year plant sampling was found to be apparently much more consistent than spider web survey. This might be explained by the low abundance of predators in spider webs in 2002.

\section{Advantages of spider-web surveys:}

a) Efficiency: according to our experience, it was easier and faster to concentrate on one model species (T. impressum) during field sampling than on a given group of arthropods (e.g., all predatory insects or all phytophagous insects). Nevertheless, this simple web survey provided information on a wide range of foliage-dwelling insects (a minimum of 18 predatory and 42 non-predatory insect families; $1.5-2$ person hour/plot/week) compared to whole plant visual sampling (a minimum of 13 predatory and 8 non-predatory insect families; $2-3$ person hour/plot/ week). If there is any non-target arthropod taxon affected by the $B t$ transgene, a quantitative sampling method for a broader spectrum of arthropods may have an increased probability to detect the difference.

b) Selectivity and activity-density: personal skills do not influence the selectivity of a spider web survey. Theoretically, in the case of extensive studies, a spider web survey may result in an increased consistency of samples compared to visual plant survey, such as when the whole sampling cannot be done by the same person, but must be done by a group of field workers instead. The daily activity patterns of insects can cause another problem typical in extensive field studies: if the number of field workers is limited, then the first plot is sampled in the morning, and the last plot is finished in the evening. T. impressum webs provide cumulative data, so time and date of sampling does not bias activity-density values. c) Additional data: spider webs contain empty egg sacs and larval exuvia of T. impressum, so additional information on reproductive output of the species in experimental plots can be obtained by sampling webs. Such an estimate of reproductive output might be a potentially sensitive measure of the integration of positive and negative trophic effects of transgenic crops on phytophagous and predatory insects.

\section{Disadvantages of spider web surveys:}

a) Efficiency: during our survey, the most obvious disadvantage was that identification of prey remnants was more problematic and time-consuming in the laboratory and required more expertise than identification of live-collected arthropods in whole plant visual sampling, so in some taxa only the family could be identified and not the species.

b) Selectivity and activity-density: the other remarkable disadvantage was that, without a sophisticated calibration procedure (which is still not available) spider web content does not provide relevant information about natural proportions and absolute density data of foliagedwelling predatory insects. However, the latter is not a substantial drawback in comparative studies, when neither natural proportions nor absolute density data are necessary to estimate, and only the differences between treatments is needed. A more considerable disadvantage is that we cannot influence selectivity, nor do we know the possible influencing factors. A prey taxon that is preferred by the spider might reach an extremely high activity-density in the field and become super-dominant in the webs. As a consequence, capture rates of the main target groups of the study drop substantially and the low numbers of individuals invalidate statistical analysis. In visual plant sampling this is not a problem, where we can ignore any non-interesting arthropod group in order to increase "capture rates" of the target groups of the study. A spider web survey is sensitive to both prey capture rates and prey disappearance rates (the rate that captured prey disappear from the web). If disappearance rates decline as capture rates decline, the actual numbers found in webs could stay the same over significant ranges of activitydensity. One factor that might cause selective prey-disappearance is the presence of non-prey scavengers (larvae of Col.: Dermestidae in our samples), which are attracted by carcasses in the web and selectively remove some prey. Another problem is the lack of webs, which can happen if spider density is too low or stormy winds or heavy rains destroy the webs. Finally, in a habitat that is 
(a)
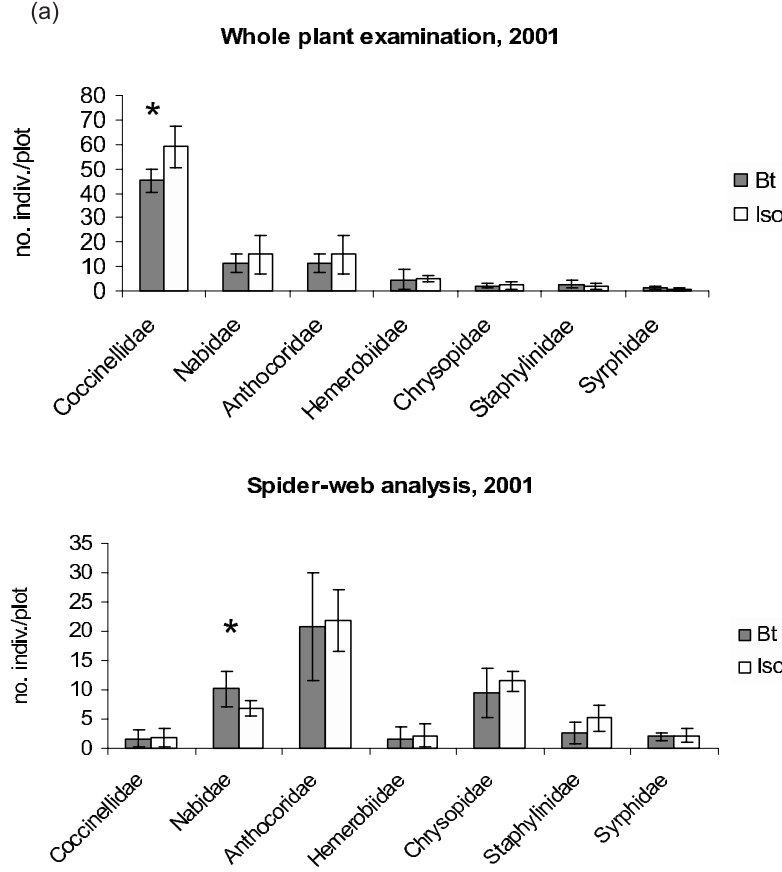

(b)

Whole plant examination, 2002

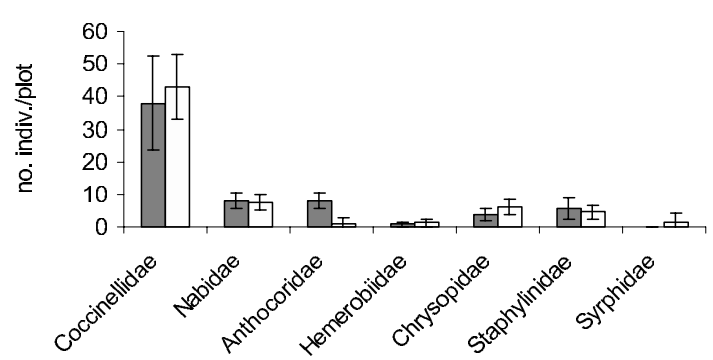

Spider-web analysis, 2002

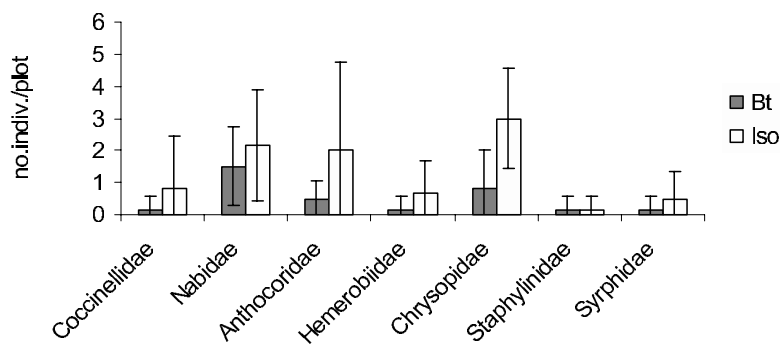

Figure 1. Comparison of the web content of Theridion impressum with whole plant visual sampling in $B t$ and isogenic corn stands in Sóskút, Hungary (selected predatory taxa, 6 replicates, average \pm SD). Asterisks indicate significant differences (Welsh test, $P<0.05$ ). structurally more complex than a weed-free corn stand, detection of $T$. impressum webs could fail.

c) Additional data: while in visual plant sampling we have the chance to observe live animals prior to collecting or recording them, spider web surveys tell nothing about the behavior, microhabitat, nutritional or reproductive state, brightness of coloration, or any other parameter that is undetectable on the dead prey but could be abnormal, even if activity-density is not different between treatments. This "blindness" can lead to misinterpretation of any result.

\section{Research needs}

The following characteristics must be tested to validate spider web surveys as an impact assessment tool: consistency of web content (similar conditions result in similar prey composition); capture and disappearance rates in different circumstances; accuracy of the method; behavior of the spider, potential prey and captured prey arthropods in the surveyed habitats; and reproductive history of $T$. impressum in correspondence with preying and feeding history. Finally, additional research is needed to determine when it is necessary in impact assessment studies to sample the prey species that are sampled by spider webs.

\section{CONCLUSIONS}

Comparison of the two methods has shown that spider web surveys do not coincide with the composition of predatory arthropod assemblages determined by whole plant sampling. If whole plant visual sampling is acceptable as a reference method, then spider web content reflects a strongly biased sample of the arthropod assemblages. Our argument against visual plant survey as a reference sampling method is that, it underrepresents camouflaged and fast moving predatory taxa (e.g., Anthocoridae), and overrepresents highly visible and slow-moving other taxa (e.g., Coccinellidae).

One can detect minor differences between $B t$ and isogenic plots with both methods, but not in the same taxa; thus, the methods did not confirm each other. The discrepancy can be explained by the different sensitivity and selectivity of the two methods. Taxa that move, jump or fly fast and can escape rapidly from the plant could be underestimated by a visual plant sampling. Taxa that are scarcely walking on the plant surface or taxa with too small or too large a body could be underrepresented in the webs of $T$. impressum. 

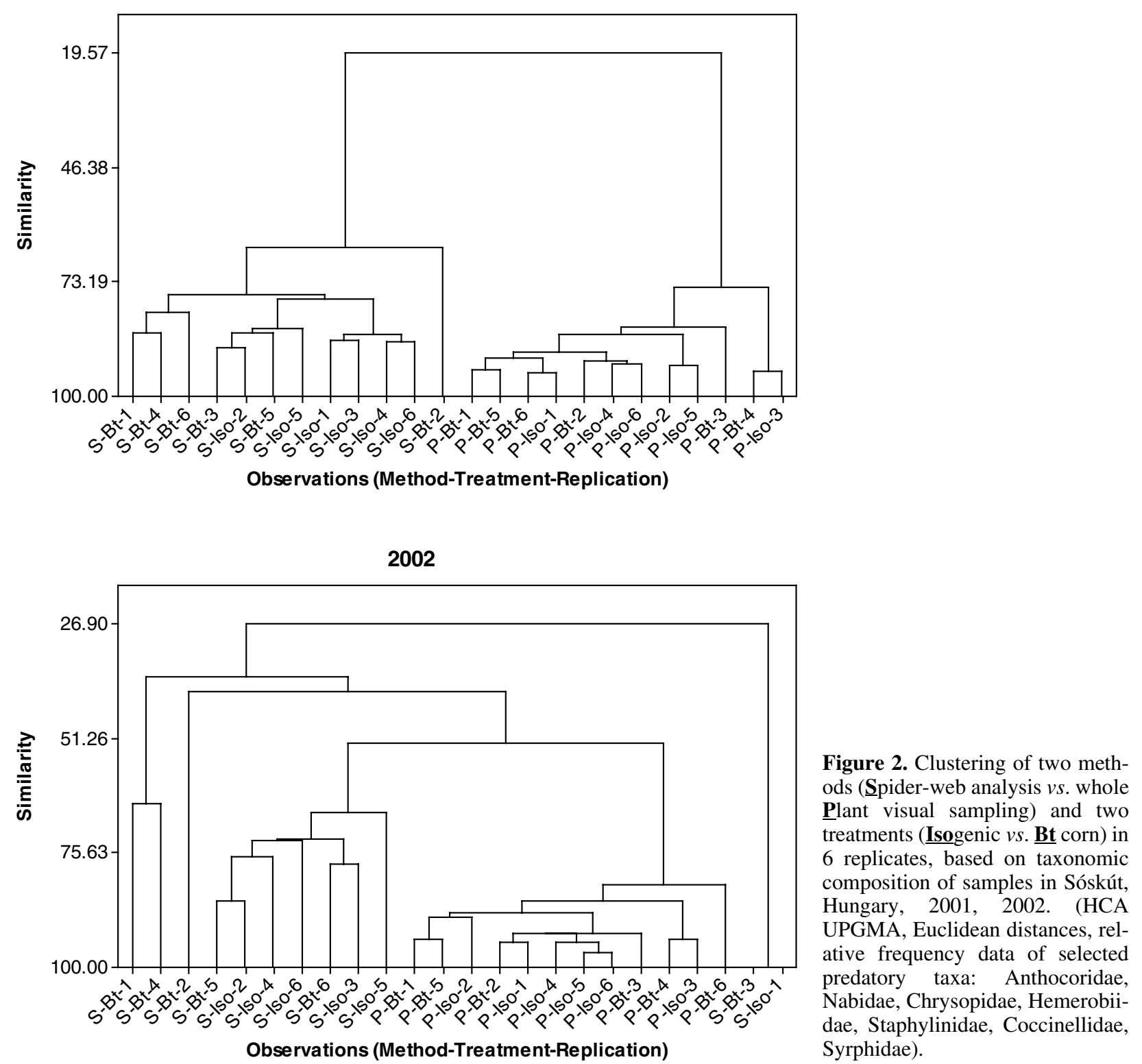

Web surveys of $T$. impressum have the practical advantage that, although we concentrate only on the model species during field sampling, we gain additional information on a wide range of foliage-dwelling arthropods. However, differences or similarities between $B t$ vs. isogenic samples detected by spider web analysis are far more problematic to interpret and explain than in the case of the whole plant visual sampling. This biological uncertainty is the result of the high number of undiscovered or unexplored factors that could affect selectivity, sensitivity and consistency of spider web content. Thus, additional research - based on in-situ observation and recording of $T$. impressum-prey interactions - is necessary before we could propose the web survey method as a complementary tool in ecological impact assessment.

\section{MATERIALS AND METHODS}

Transgenic (DK 440 BTY, event MON 810) and isogenic (DK 440) corn plots were sampled for spider-webs and 
foliage-dwelling insects in 2001 and in 2002, in Sóskút, Hungary. The $B t$ corn was released under with relevant permits. There were 6 replications, resulting in a total of 12 complete block plots. Plot size was $30 \times 30 \mathrm{~m}$ (50 000 plants/ha).

\section{Spider-web survey}

In each plot, 500 individual corn plants were visually checked weekly between June 28 - August 29, 2001, and from June 27 to September 25, 2002. The corn anthers simplify the recognition of the web of $T$. impressum, which, being woven of thin threads is otherwise hardly visible. In 2001 and 2002, the number of webs examined (collected) was 475 and 135, respectively. During both years, prey caught in the web was determined down to the family level using microscopes. Non-insect arthropods, non-predatory insects and non-prey items (found in the web but not bound by the spider, e.g., lacewing eggs and pupae, syrphid pupae) were not involved in the present study.

\section{Whole plant visual sampling}

Randomly selected corn plants (10 plants/plot/week) were visually checked and counted for insects. In order to find hiding insects as well, leaves, tassels and ears of the corn plants were removed and dissected after surface examination. All insect taxa were sampled or recorded; predators were identified to the species level, but only family level information was used in the present comparative analysis.

\section{Analysis}

Periods when only one sampling method was used were excluded from analysis.

Based on taxonomic composition (relative frequencies of different taxa in each plot) Hierarchical Cluster Analysis with Un-weighted Pair Group Method with Arithmetic Mean (HCA UPGMA, Euclidean distances) and Non-metric Multidimensional Scaling (NMDS, Euclidean distances) was used to test if plots could be separated by method (spider web vs. plant sampling) or by treatment (Bt vs. isogenic).

The comparison of insect assemblages of $B t$ and isogenic plots was based on the cumulative data of each plot using a two-sample t-test with Welch's correction. To avoid the problem of pseudo-replications, each plot was considered as one replicate and not individual plants or webs.

\section{ACKNOWLEDGEMENTS}

The authors would like to express their warm thanks to István Tóth (Department of Plant Protection, Gödöllö University), for identifying web content. The EU-5 QLK3-CT-2000-00547 project and the Bolyai János Research Grant (to F. Tóth) supported this study. The content of this publication is the sole responsibility of its authors, and in no way represents the views of the Commission or its services.

Received August 27, 2004; accepted March 25, 2005.

\section{REFERENCES}

Árpás K, Tóth F, Kiss J (2004) Analysis of web content of Theridion impressum L. Koch (Araneae: Theridiidae) in BT (DK 440 BTY, MON 810, Cry1Ab) and isogenic (DK 440) maize. IOBC wprs Bulletin 27: 23-29

Bogya S (1999) Spiders (Araneae) as polyphagous natural enemies in orchards. Ph.D. thesis. University of Wageningen, Wageningen.

Bogya S, Mols PJM (1996) The role of spiders as predators of insect pests with particular reference to orchards: A review. Acta Phytopathol. Entomol. Hung. 31: 83-159

Bourguet D, Chaufaux J, Micoud A, Delos M, Naibo B, Bombarde F, Marque G, Eychenne N, Pagliari C (2002) Ostrinia nubilalis parasitism and the field abundance of nontarget insects in transgenic Bacillus thuringiensis corn (Zea mays). Environ. Biosafety Res. 1: 49-60

Candolfi MP, Brown K, Grimm C, Reber B, Schmidli H (2004) A faunistic approach to assess potential side-effects of genetically modified $B t$-corn on non-target arthropods under field conditions. Biocontrol Sci. Technol. 14: 129-170

Dively GP, Rose R (2002) Effects of $B t$ transgenic and conventional insecticides on the natural enemy community in sweet corn. In: M.S. Hoddle (ed.): 3rd CCBC, Canada, pp 9-15

Dutton A, Romeis J, Bigler F (2003) Assessing the risks of insect resistant transgenic plants on entomophagous arthropods: $B t$-maize expressing $\mathrm{Cry} 1 \mathrm{AB}$ as a case study. BioControl 48: 611-636

Greenstone MH (1999) Spider predation: how and why we study it. J. Arachnol. 27: 333-342

Hanggi A, Stockli E, Nentwig W (1995) Lebensräume mitteleuropäischer Spinnen. Miscellanea faunistica Helvetiae 4, CSCF, Neuchâtel, pp 1-460

Heimer S, Nentwig W (1991) Spinnen Mitteleuropas. Verlag Paul Parey, Berlin und Hamburg, pp 1-544

Hodge MA (1999) The implications of intraguild predation for the role of spiders in biological control. J. Arachnol. 27: 351362

James C (2003) Preview: Global Status of Commercialized Transgenic Crops: 2003. ISAAA Briefs No. 30. ISAAA: Ithaca, NY. 
Kiss J, Szentkirályi F, Tóth F, Szénási Á, Kádár F, Árpás K, Szekeres D, Edwards CR (2003) Bt Corn: Impact on nontargets and adjusting to local IPM systems. In: Ecological impact of GMO dissemination in agro-ecosystems, Lelley T, Balázs E, Tepfer M Eds. Facultas Verlags und Buchandels AG, Wien, Austria, pp 157-172

Lozzia GC (1999) Biodiversity and structure of ground beetle assemblages (Coleoptera, Carabidae) in Bt corn and its effects on non-target insects. Boll. Zool. agr. Bachic., 31: 37-58

Lozzia GC, Rigamonti IE (1998) Preliminary study on the effects of transgenic maize on non target species. IOBC wprs Bulletin 21: 171-180

Lozzia GC, Furlanis C, Manachini B, Rigamonti IE (1998) Effects of Bt corn on Rhopalosiphum padi L. (Rhynchota Aphididae) and on its predator Chrysoperla carnea Stephen (Neuroptera Chrysopidae). Boll. Zool. Agr. Bachic. 30: 153164

Ludy C, Lang A (2004) How to catch foliage-dwelling spiders (Araneae) in maize fields and their margins: a comparison of two sampling methods. J. Appl. Entomol. 128: 501-509

Manachini B (2000) Ground beetle assemblages (Coleoptera, Carabidae) and plant dwelling non-target arthropods in isogenic and transgenic corn crops. Boll. Zool. Agr. Bachic. 32: $181-198$

Nyffeler M (1999) Prey selection of spiders in the field. $J$. Arachnol. 27: 317-324

Nyffeler M, Benz G (1988) Feeding ecology and predatory importance of wolf spiders (Pardosa spp.) (Araneae, Lycosidae) in winter wheat fields. J. Appl. Entomol. 106: 123-134

Nyffeler M, Sunderland KD (2003) Composition, abundance and pest control potential of spider communities in agroecosystems: a comparison of European and US studies. Agric., Ecosyst. Environ. 95: 579-612

Nyffeler M, Sterling WL, Dean DA (1994) How spiders make a living. Environ. Entomol. 23: 1357-1367

Pekár S (1998) Effect of selective insecticides on the beneficial spider community of a pear orchard in the Czeh Republic. Proceedings of the 17th European Colloquium of Arachnology, Edinburgh, P.A. Selden Eds. 337-342

Pekár S (1999) Foraging mode: a factor affecting the susceptibility of spiders (Araneae) to insecticide applications. Pestic. Sci. 55: 1077-1082

Pekár S (2000) Webs, diet, and fecundity of Theridion impressum (Araneae: Theridiidae). Eur. J. Entomol. 91: 47-50

Pekár S (2002) Susceptibility of the spider Theridion impressum to 17 pesticides. Anz. Schädlingskd. 75: 51-55
Pilcher CD, Obrycki JJ, Rice ME, Lewis LC (1997) Preimaginal development, survival, and field abundance of insect predators on transgenic Bacillus thuringiensis corn. Environ. Entomol. 26: 446-454

Roberts MJ (1995) Spiders of Britain and North Europe. Harper Collins, London, pp 383

Samu F, Szinetár CS (1999) Bibliographic check list of the Hungarian spider fauna. Bull. Br. Arachnol. Soc. 11(5): 161-184

Schröder TW, Basedow T, Mangali T (1999) Population density of Theridion impressum L. Koch (Araneae, Theridiidae) in sugar beet fields in Germany, and its possible effects on numbers of Myzus persicae (Sulzer) (Hom., Aphididae). J. Appl. Entomol. 123: 407-411

Sunderland KD, De Snoo GR, Dinter A, Hance T, Helenius J, Jepson P, Kromp B, Lys J-A, Samu F, Sotherton NW, Toft S, Ulber B (1995) Density estimation for invertebrate predators in agroecosystems - Arthropod natural enemies in arable land I. Acta Jutlandica 70: 133162

Tóth F, Tuska T, Kiss J (2001) Effect of Theridion impressum (Araneae: Theridiidae) on the silk clipping of Diabrotica virgifera virgifera adults in hybrid seed corn in Hungary. IWGO Newsletter 22: 17

Tóth F, Horváth L, Kiss J, Edwards CR (2000) Potential impact of Enoplognatha latimana (Araneae: Theridiidae) on the silk damage caused by Diabrotica virgifera virgifera adults. IWGO Newsletter 21: 30

Tóth F, Horváth L, Komáromi J, Kiss J, Széll E (2002) Field data on the presence of spiders preying on western corn rootworm (Diabrotica virgifera virgifera LeConte) in Szeged Region, Hungary. Acta Phytopathol. Entomol. Hung. 37: 163-168

Tóth F, Tálasné Tóth J, Kiss J, Edwards CR (1998) Preliminary study on spiders as natural enemies of western corn rootworm (Diabrotica virgifera virgifera LeConte) adults in Hungary. IWGO Newsletter 18: 22

Volkmar C, Traugott M, Juen A, Schorling M, Freier B (2004) Spider communities in Bt maize and conventional maize fields. IOBC wprs Bulletin 27: 165-170

Wold SJ, Burkness EC, Hutchison WD, Venette RC (2001) In-field monitoring of beneficial insect populations in transgenic corn expressing a Bacillus thuringiensis toxin. $J$. Entomol. Sci. 36: 177-187

Zschokke S (2002) Form and function of the orb-web. European Arachnology 2000 (Toft S \& Scharff N Eds.) Aarhus University Press, Aarhus, pp 99-106 